\title{
English Language Programmes for Refugees in St. John's, Newfoundland
}

\author{
Tonya Bassler
}

\begin{tabular}{|c|c|}
\hline $\begin{array}{l}\text { Refugees who have St. John's, New- } \\
\text { foundland, as their first place of residence } \\
\text { in Canada often have inadequate or no } \\
\text { English language skills. Several pro- } \\
\text { grammes are available to speed their tran- } \\
\text { sition into Canadian societv. To a certain }\end{array}$ & $\begin{array}{l}\text { extent the programmes overlap, but each } \\
\text { is also distinct and serves different } \\
\text { specified needs of the refugee community. } \\
\text { This paper examines the strengths and } \\
\text { weaknesses of each programme. }\end{array}$ \\
\hline
\end{tabular}

Canada's Immigration Act of 1976 defines a refugee as anyone who is afraid to return to his or her country "by reason of a well-founded fear of persecution for reasons of race, religion, nationality, membership in a particular social group or political opinion."

Adult refugees living in St. John's, Newfoundland, can avail themselves of several different English language acquisition programmes. Why are there several programmes instead of an all-encompassing one? Do the programmes attempt to serve different needs or are they unnecessarily repetitious? Even more important from the perspective of refugees, to what extent are these programmes actually meeting their needs? This paper proposes to answer these questions by examining the programmes one by one, and, in so doing, focusses specifically on those refugees who qualify for federal government settlement assistance.

The four programmes that cater to them are the (1) CEIC (Canada Employment and Immigration Commission)-sponsored, full-time English as a Second Language (ESL) Program, (2) the Settlement Language Training Program (SLTP), (3) the Volunteer Tutor Program, and (4) the TOEFL (Test of English as a Foreign Language) preparation course.

\section{Methodology}

In order to answer the questions raised in this paper, I relied chiefly on interviews and classroom observations. On numerous occasions I queried Canada Immigration's chief of Settlement for Newfoundland; I am grateful for his patience with me and for the painstaking manner with which he clarified policies and statistics for me. Others whom I interviewed throughout 1989 included those involved that year with the four programmes: administrators, tutors, all the instructors, two SLTP babysitters, and last 
but most definitely not least, many of the refugees who were or aspired to be participants. In 1989 I myself twice instructed the TOEFL preparation course; the students gave me invaluable feedback on the extent to which the course was meeting their felt needs. In addition, as an instructor in the daytime ESL Program, I have regular contact with refugees, and I also keep in touch privately with many of them. The SLTP instructors, as well as my ESL colleagues, allowed me to observe and to participate, if I wished, in their classrooms.

My interviews were all conducted orally. When I interviewed those responsible for delivering the programmes, I wanted to be able to press for direct, nonevasive, insightful answers. With written questionnaires, I could not have so readily pursued clarification of ambiguity.

Particularly with the refugees, I deliberately avoided written questionnaires. First of all, I would judge the English proficiency of most of them to be at the beginning to intermediate level. This would limit the meaningfulness of their answers to an English-language questionnaire. Second, Brookfield (1986: 53-54) reflects my own concerns when he recommends "an open-ended, conversational style of interviewing" rather than the use of "standardized instruments" with "members of ethnic minorities, or recently arrived immigrant groups" because their probable suspicion of such devices is unlikely "to foster the atmosphere of trust and reciprocity necessary to an authentic research encounter". Blanchard (1988) gives additional support for the nonuse of standardized questionnaires. Anyone in contact with refugees should keep in mind, she contends, that they have developed a suspiciousness of official-looking forms because of their "fear of betrayal." I value the apparent candor with which the refugees voiced their hopes, needs, and experiences to me; out of respect for their frankness and in recognition of their vulnerability, I have not identified them by name.

\section{Background}

Although far removed from the bustle of Canada's centre and populated predominatly by descendants of immigrants from the British Isles, St. John's provides the first Canadian place of residence for a steady trickle of refugees from all over the world. In each of the years 1987, 1988, and 1989 approximately 150 refugees in St. John's received federal government settlement assistance, according to the Department of Immigration's chief of Settlement for Newfoundland (G. Budden, personal communication, September 18, 1989, and April 27, 1990). His figures show that about half of the refugees in each of these years arrived from overseas via normal immigration channels as part of Canada's refugee quota, while defectors from flights at Gander International Airport comprised the rest. 
In other words, a discussion of refugees in St. John's concerns a yearly number of about 150 arrivals, of whom around half are planned for by Immigration officials and another half are unexpected. Adults are an estimated eighty percent of the annual total (G. Budden, personal communication, April 27, 1990).

These annual arrivals in St. John's often have inadequate or no English language skills. The problems created by their minimal English language capabilities are frequently compounded by their bewilderment in daily dealings with what is to them an essentially alien-although, perhaps superficially, a deceptively familiar-Canadian culture. Indeed, the federal government recognizes that refugees have varying needs and that different programmes are needed to respond to these needs.

To speed their transition into this new society, several programmes-all voluntary for the participants-of English language acquisition assistance are available for adult refugees. One programme targets those anxious to enter the work force as soon as possible, another is directed at those not intending to seek employment, a third involves volunteers on a one-to-one basis and a fourth prepares students to enter the academic stream.

In the long run, the Settlement Branch of the Department of Immigration wants refugee immigrants to be able to cope with life anywhere in Canada as well as native-born Canadians can (G. Budden, personal communication, March 14, 1989). Thus the Settlement Branch is very concerned that, while they are in Newfoundand, the refugees develop not only the skills they need immediately in Newfoundland but also those they might later require on the mainland to cope as well as native-born Newfoundlanders who migrate to the mainland. This objective is particularly significant because within a year or so of arrival the Settlement Branch records about seventy persent of the refugees leaving the province for the mainland.

Handscombe (1988) emphasizes that adult refugees are possessed by the consuming need to get a job. She relates this to their self-identification: in most societies persons define themselves and are defined by their job. Consequently, for more than economic reasons Handscombe considers it "almost impossible" for an adult refugee not to worry about finding employment.

\section{The English as a Second Language Programme}

The intensive English as a Second Language (ESL) Program at the Avalon Community College in St. John's caters to this need. Initiated in 1979 as the plight of the Vietnamese boat people became increasingly urgent, it operates five days a week year round. With the intention of bridging the language and cultural shock of new Canadians and of preparing them to enter the Canadian work force, this ESL programme with its 
five instructors provides a learning environment that includes a language lab and computers in addition to regular classrooms.

The ESL Curriculum Guide of the Avalon Community College specifies that the goal of the programme "is to ease the New Canadian's transition into Canadian society" (Avalon Community College, 1984, p. 1). This is to be approached in a two-pronged manner that combines the important language "skills of listening, speaking, reading, and writing necessary for living and working in a predominantly English Canadian milieu" with the equally important understanding of Canadian cultural life.

Because of the wide variety in English and literacy skills among incoming participants, instructors are expected to help each refugee identify individual learning needs and to suggest appropriate activities to meet the identified needs (Avalon Community College, 1984, p. 2). That is to say, class programmes are flexible, individualized and subject to ongoing reassessment by both participants and instructors in consultation with one another (E. Bragg, personal communication, February 18, 1988; August 22 and September 20, 1989). In keeping with the enunciated multicultural policy of the federal government, the ESL instructors strive to avoid imposing assimilation or "melting pot" behaviour. Participants are encouraged to maintain their non-Anglo ethnicity, which their instructors respect both as a valuable building block for future learning and as a potential force for positive contributions to Canadian life (E. Bragg, personal communication, August 22, 1989).

A significant component of the programme concerns the preparation of participants for successful employment. For many of them it is intially difficult to comprehend the necessity in Canadian culture to sell yourself, regardless of credentials. Resumes, job interviews, acceptable behaviour at work-to name a few-are all critical but unfamiliar concepts for many refugees.

The ESL Program operates on a continuous intake/exit system. Preentry and exit evaluations covering listening, speaking, reading, and writing skills are conducted on an individual basis by the head instructor. The pre-entry evaluation determines the placement of the refugee in the beginning, intermediate, or advanced class. Although the usual length of stay in the program is six months, a participant might progress faster and thus leave earlier. On the other hand, a participant needing more time can obtain an extension for up to another six months.

During the exit interview the head instructor not only carries out a final evaluation of the refugee but also offers counselling for the future. Career objectives are discussed in practical terms, other ongoing sources of language and adjustment help are indicated and programmes available in other provinces are outlined (E. Bragg, personal communication, February 18, 1988). 
With the above ESL programme embodying such a comprehensive yet flexible approach to refugees' language and cultural adjustment, it might seem reasonable to ask why refugees take part in any other programmes.

First of all, not every refugee is job oriented at that moment in life. In addition to the minority, e.g., traditional homemakers, who have no intention of ever seeking employment, some refugees prefer to postpone participation in the Avalon Community College's ESL Program until they have resolved distractions that would likely interfere with the motivation and concentration they need to participate in this intensive, daily programme. For instance, health problems or family responsibilities might be temporarily overwhelming.

Second, for a number of years refugees have usually had to wait at least three months before a sponsored seat is available in the ESL Program. Because the number of seats is frozen now by Canada Employment and Immigration Commission (CEIC) at thirty (that is, refugees sponsored by CEIC are limited to thirty places), even though the ESL Program accommodates more students than thirty at any one time, a waiting refugee can enter the programme only when someone exits. Although CEIC funds the seats 100 percent and also pays the refugees a weekly allowance, as well as a babysitting subsidy if necessary, while they are studying in the programme, the thirty seats sponsored in this manner are simply insufficient to reduce the backlog of waiting refugees. The refusal of the federal government to purchase more seats does not necessarily reflect fiscal wisdom because the federal government itself provides the financial support for the refugees during the waiting period. This long delay merely prolongs their transition to financial independence. The sooner they could enter the programme and complete it successfully, the greater the benefit to them in terms of personal satisfaction and the greater the gain to Canada in every respect.

Refugees often find this period of being in limbo an acutely depressing and demoralizing time. They want to get on with their lives and be in control of their fate and yet, day after day, they sit and wait. For those in dire need of the most basic English skills, the wait magnifies the problems of adjustment. Those with a modicum of English chafe at the delay. Some leave abruptly for the mainland in search of jobs even though they are disadvantaged by their lack of ESL study. The refugees who stay in St. John's and wait express a desperate need to emerge from the cultural and language isolation of their apartments.

\section{The Settlement Language Training Program}

For many refugees, the makeshift answer is the second programme this paper examines. The Settlement Language Training Program (SLTP) pro- 
jects are intended to meet the language and social needs of adult immigrants who are not expected to join the work force. In fact, "immigrant women at home" constitute the specific priority target group (CEIC, 1986). Introduced as a national pilot programme throughout Canada in late 1986 and early 1987 by the Settlement Branch of CEIC, in St. John's the SLTP projects are delivered by the Association for New Canadians, the local community settlement agency. Although-unlike job-entry ESL provisions-participants do not receive the motivation of financial remuneration for their attendance, the SLTP allows the delivery agency to fund, as part of its project, two support services: (1) free babysitting and (2) free transportation. Fifteen to twenty eligible participants are necessary in order to implement any project (G. Budden, personal communication, March 14, 1989, and September 18, 1989).

The Association in St. John's has delivered one SLTP project after another since December 1986, and, in fact, during the second half of 1989 two projects ran simultaneously (G. Budden, personal communication, March 14, 1989, and September 18, 1989). The projects are in operation on the Association's premises, which are in an area of the city where many recent refugees tend to live. The babysitting room is also on the premises. The classes meet mornings five days a week. The SLTP instructors employed have met the Avalon Community College's ESL qualifications, according to the Association's executive director, who adds that the babysitter is likewise expected to have some kind of recognized day-care training and experience (B. Foster, personal communication, September 14, 1989).

As a visitor to the SLTP classrooms on five occasions in a recent eightmonth period, I could not help noting the Spartan-like furnishings and the virtual absence of modern teaching aids. Nevertheless, the extreme warmth of the very informal classroom atmosphere was also obvious. Participants chattered animatedly among themselves and with the instructor. Preschool children were free to wander in and out to be hugged by their parents and admired by the others. One very young infant was in the classroom with its mother the whole time-much to the delight of the other participants. Ready accessibility to each other appeared to be important to parents and children alike. According to one instructor, the smooth functioning of the project hinges on the parents' satisfaction with the babysitter (J. Kergoat, personal communication, February 9, 1989). The lessons concentrated on everyday English in everyday Canadian situations with the long-term goal of increasing all four of the English language skills. Field trips are sometimes arranged as a further means of developing language, cultural and social skills.

Although SLTP is designated for immigrant women at home (and these could be refugee women with landed immigrant status), in St. John's 
many who commonly attend are refugees on CEIC's job entry ESL waiting list. Moreover, in the sessions I visited, none of the refugees in attendance fell into the target category. On the contrary, virtually all of them, including the mother with the infant, indicated that they were on CEIC's waiting list. To give some examples, they comprised in one session eight out of eleven participants; in another, two out of thirteen, in a third, nine out of sixteen; in a fourth, eight out of fifteen; and in a fifth, six out of fourteen. Altogether in these five sessions, waiting refugees amounted to thirty-three of the sixty-nine in actual attendance or nearly one half. What appears to be happening in St. John's, then, is that refugees on CEIC's list turn in the interim to local SLTP projects for relief from language and social isolation.

This situation is viewed sympathetically by those who are responsible for SLTP in St. John's because the SLTP projects aim to help immigrants emerge from isolation. The executive director of the Association acknowledges that "waiting for langauge training is the killer. Psychologically, it is very valuable for people to be doing something" (B. Foster, personal communication, September 14, 1989). With regard to actual participants in the SLTP projects, Immigration's chief of Settlement concedes that "flexbility is the word" (G. Budden, personal communication, September 18, 1989). Although refugees on CEIC's waiting list cannot be included in an SLTP project application, in actual practice refugees are not denied entry once the project is underway, as long as sufficient seating space is available. For them as well as for refugee women who intend to remain homemakers and who would therefore be bona fide participants, the chief of Settlement recognizes that the SLTP projects give them something to do and get them out of the isolated home environment. The fact that many refugees return day after day to the SLTP setting indicates how worthwhile they find the experience in meeting their needs. Because of their circumstances, many seem to be at the so-called "teachable moments" in their lives when they are poised, seriously ready to learn (Zemke \& Zemke 1981). These SLTP projects provide that opportunity for those not being served by another ESL arrangement during the day.

Essentially, the local SLTP projects address the social isolation, language learning and cultural adjustment of new Canadians, many of whom are recent refugees seeking help with this adjustment. The popularity of these projects with refugees in St. John's exemplifies how relatively successful a frugally operated federal project can be in meeting actual participants' needs.

On April 1, 1990, the federal government changed the status of SLTP nationally from a temporary to a regular programme and altered its name to Settlement Language Program (SLP) (G. Budden, personal communication, April 27, 1990). This change in status brings a certain stability to the 
programme and consequently those involved with the local projects are now able to indulge in long term planning. It remains to be seen to what extent refugees in St. John's will continue to have access to it.

A class size of around ten to twenty participants is the norm in the two programmes examined so far in this paper. With such a class size it is understandable that no participant can receive the undivided attention of the instructor for an extended period of time.

\section{The Volunteer Tutor Program}

The Volunteer Tutor Program, the third programme this paper examines, has been attempting to fill the need by refugees for intensive, individualized adjustment assistance. In existence for the past four years, the Volunteer Tutor Program is funded by the Secretary of State and-like the SLTP projects-sponsored by the Association for New Canadians. A refugee of any age is eligible to be matched with a community volunteer who agrees to provide one-on-one assistance for a minimum of two hours per week. Coordinated by a settlement agency employee whose position is funded six hours per week for this work, the Volunteer Tutor Program makes available about fifteen tutors at any given time, except in the summer when their numbers dwindle. The coordinator estimates that twentyfive tutors would be adequate to cover requests (P. Campbell, personal communication, September 14, 1989). Because the needs of the participants vary so much, the main-and the only required-qualification for the tutor is the interest to help with cultural information and language acquisition. Quite often the tutor acts somewhat like an advocate for the refugee in community situations.

According to the coordinator, the tutoring programme is organized in the following manner (P. Campbell, personal communication, September 14, 1989). In her capacity as a settlement agency worker, during her "initial counselling" with the refugee, she informs the person of the tutoring possibility and asks if he or she is interested in being paired. The coordinator then matches refugee with tutor. Regardless of the refugee's English proficiency level, the coordinator claims that a refugee who wants a tutor would never be turned away because the programme "is not entirely fixed on language" (P. Campbell, personal communication, September $18,1989)$. Interestingly, according to her, a refugee occasionally rejects the notion of a tutor from the refugee's own language background, especially if the prospective tutor was an immigrant to Canada at one time; he wants a "bona fide Canadian"! (P. Campbell, September 14, 1989). The coordinator recruits volunteers in St. John's through (1) the Community Services Council, (2) Memorial University of Newfoundland's Student Volunteer Centre, (3) newspapers, and (4) posters. Because of the tutors' 
varied personal schedules, the coordinator consults with them monthly on an individual basis rather than as a group. She also supplies them with a handout of suggestions although she considers the programme's lack of format an asset in providing individualized and specialized contact.

My conversations with tutors and recipients reveal that, at its best, both parties can find the relationship rewarding and meaningful. However, sometimes it fizzles out after only one encounter. Some refugees told me they were too embarrassed to request another tutor-they indicated to me that they somehow felt to blame for the failure of the relationship. Others did not realize they could request another tutor.

The Volunteer Tutor Program embraces laudable goals and has the potential to be a valuable complement to both the job entry ESL Program and the SLTP projects. However, discrepancies exist now between the promise of services and the actual delivery of them.

During the course of my research, numerous refugees complained vehemently that their requests for tutors had fallen on deaf ears. Many expressed an urgent need for the individualized assistance a tutor could give. One refugee, who was ready to exit the ESL Program and look for employment, related bitterly that he had asked for a tutor months ago, but had never received one. Another reported that she had been waiting for a tutor for the past four months. A third told me, "I asked the Association for a tutor, but they told me my English was too good, that I didn't need one" (Cuban refugee, personal communication, May 5, 1989). This is a revealing comment since it directly contradicts the coordinator's abovementioned assertion that a refugee's perceived level of English proficiency would never cause ineligibility because the programme is "not entirely fixed on language."

Quite a few refugees claimed to be completely unaware of the Volunteer Tutor Program, despite the previously mentioned assertion of the coordinator that she informs each refugee of it during her "initial counselling." When I questioned them in various ESL and SLTP classes, few knew about it. For example, in one class only two of seven refugees, in a second class three of ten, and in a third class none of eight knew about the tutor programme. At the same time, when informed about it, nearly all (seven of seven, seven of ten, and eight of eight respectively) expressed a strong interest in being matched with a tutor. In fact, my questions to the students provoked such an overwhelming flood of interest in being immediately paired with a tutor that it was quite embarrassing for me to have to communicate to them that I did not have tutors on hand for them, that I merely wanted to know if they would be interested in having tutors.

Based, then, on what refugees have told me, the Volunteer Tutor Program, as it now functions, could be more effective in needs fulfillment than it is now. 
How could this be rectified? The core problems afflicting the programme seem to revolve around the relatively limited quality time allotted to it by the coordinator. If a tutoring programme is to be successful in meeting the felt needs of the 150 or so annual refugees, it must have an enterprising coordinator who can devote more than the presently funded six hours a week to informing the refugees about it, recruiting tutors, and monitoring the refugee-tutor relationships. The previous coordinator suggested the position requires at least twenty hours of undivided attention per week (F. Locke, personal communication, September 19, 1989). The present coordinator sees it ideally as a full-time position (P. Campbell, personal communication, September 14, 1989). Since the coordinator is employed by the Association, she is vulnerable to other pressing settlement demands. Perhaps settlement employees view this programme as a project-not needing aggressive concentration-that can be neglected on a back burner. The coordinator's shortage of time almost certainly contributes to the fact that many refugees, according to their own admission, 1) are not informed of the tutoring possibility, and 2) are ignored when they do make the request. Moreover, the time factor might also be responsible for the rather passive or indifferent recruitment of tutors. My check with Memorial University's Student Volunteer Centre initially revealed no request on file for students to volunteer as tutors for immigrants, refugees, New Canadians, etc. An intensive search at my insistence finally located the request: it was listed under the Association for New Canadians. However, unless someone wishing to volunteer tutoring services at the Centre is specifically directed to the Association listing (and I was not), a prospective tutor remains unware of the need. An energetic coordinator could ensure by repeat phone calls that all recruitment listings are cross-referenced under the listing of tutor. Significantly, the former coordinator found that her most successful recruitment "came from among friends" (F. Locke, personal communication, September 19, 1989), whereas the present coordinator gave no indication at all of active personal recruitment of tutors.

Based on the information I uncovered, a Volunteer Tutor Program that successfully meets the expressed needs of refugees must have a full-time, energetic coordinator whose time is not subject to interference by other settlement demands. The coordinator should inform each refugee on more than one occasion about the possibility of a volunteer tutor. Because this is a new concept for most refugees, the initial explanation of it might be misunderstood with the refugee consequently unwittingly rejecting the notion or not appearing to be interested in it. Once a refugee and tutor have been paired, the coordinator cannot forget about them. On the contrary, the successful coordinator needs to provide ongoing monitoring of the relationship and to make certain that both members of the pair know 
the coordinator is available for advice if problems arise. The coordinator should also ensure that other Association workers do not provide misinformation about the programme. For example, the Cuban refugee mentioned earlier reported to me that the "Association" rejected his request for a tutor. What he termed the Association was not necessarily the coordinator; it might well have been an incorrectly informed settlement worker who should have referred the refugee to the coordinator.

The Association for New Canadians is in the process of implementing «new host programme for incoming refugees. This would match an entire local family with a refugee. Perhaps refugee needs will be better met by this new, enlarged programme and the present tutor match will be subsumed by it. As it is now, according to what refugees told me, very few of them are benefiting from the Volunteer Tutor Program.

\section{The TOEFL Preparation Course}

Those who deal with refugees know that some of them-often those with a higher educational background-experience something akin to a compulsion to perfect their English. For these refugees, a fourth programme, the TOEFL preparation course offered by the Avalon Community College and funded by the provincial government provides a challenge to develop the English comprehension skills needed in a university environment (T. Bassler, 1989). Taught by instructors qualified for the daytime ESL Program described above, this 81-hour course is offered on demand (usually two or three times a year) for a modest fee to participants. Since it is an evening course, many who enroll are also in the ESL Program or on the waiting list for it. Commonly, those on the waitting list attend the SLTP classes during the day. In the last two TOEFL courses offered, refugees comprised well over half of the students. This course seems to appeal to students who feel a need for a more academic approach to the English language. Some refugees say they take the course simply for the intellectual activity involved; however, most of them are universityintended and need to pass the TOEFL before a North American university will admit them. Many in the latter group told me that this course provides the structured format they feel they need to prepare themselves in a disciplined manner for the dreaded test. According to the students, the course's main shortcoming is its relative brevity: students often express an interest in a preparatory course of longer duration.

\section{Conclusion}

At the present time, based on my interviews and observations, no single language programme described above meets all the differing needs of all the refugees in St. John's. However, each one does meet specific needs: 
The work-related language and cultural focus of the CEIC-sponsored ESL Program addresses the employment concerns of refugees; its main drawback, which could be corrected by increased funding, seems to be its limited number of seats. SLTP concentrates on removing language and social isolation; despite its threadbare budget, many refugees rely on SLTP's supportive atmosphere in their first months and later relate fond memories of hours they spent in SLTP's projects. The Volunteer Tutor Program specializes in providing language and supportive community help on an individualized basis; unfortunately this programme has not been extended to many refugees who would like to participate in it. The TOEFL preparation course both encourages precision in language acquisition and introduces students to the North American university environment; those who perceive a need for this type of learning participate enthusiastically but lament what they term the course's insufficient length.

Although the programmes described above have objectives distinct from each other, in practice all four can actually function symbiotically to meet the various needs of an individual refugee. The following true case history illustrates this in synopsis form.

A young Bulgarian defected in Gander in the past year and was brought to St. John's for settlement assistance. With no knowledge of English, he was put on CEIC's waiting list for the ESL job-entry programme. Meanwhile, throughout the winter he attended SLTP classes regularly and applied himself vigorously to the task of learning English. He enrolled in the TOEFL evening course while during the day attending first the SLTP class and later the ESL Program. With the help of a supportive ESL instructor, he found a volunteer tutor (significantly, not through the efforts of the Volunteer Tutor Program) who helped him privately. Six months after his defection he was successful in completing the ESL Program and passing the difficult TOEFL exam. Although his case is not necessarily typical, his success story nonetheless illustrates how the four programmes can work in conjunction with one another to meet the expressed needs of an individual refugee.

\section{REFERENCES}

Avalon Community College. (1984) ESL curriculum guide. Unpublished manuscript.

Bassler, T. (1989, Summer). English proficiency requirements at Memorial University. TESL Vessel, p. 2.

Blanchard, K. (1988, April). Presentation to TESL Newfoundland/Labrador Conference. (Videotape). St. John's: Avalon Community College.

Brookfield, S. (1986). Understanding and facilitating adult learning. San Francisco: Jossey-Bass. 
Canada. Employment and Immigration Commission. (1986). "Settlement Language Training Program: Program description and guidelines." Ottawa: Employment and Immigration Commission (mimeo). As cited in Burnaby, B. (1988). Community based ESL: An assessment of a federal pilot iniative. TESL Canada Journal,6 (1), 27-39; and Burnaby, B., M. Holt, N, Steltzer, \& N. Collins, (1987). The Settlement Language Training Program: An assessment. Employment and Immigration Canada.

Canada. Immigration Act. (1976).

Handscombe, J. (1988, April). Presentation to TESL Newfoundland/Labrador Conference. (Videotape). St. John's: Avalon Community College.

Zemke, S., \& J. Zemke. (1981). 30 things we know for sure about adult learning. Training, $18(6), 45-52$.

\section{THE AUTHOR}

Tonya Bassler (B.A., M.A., University of Kansas; B.Ed., Memorial University of Newfoundland) is an instructor at the Avalon Community College in St. John's, Newfoundland. She presented this paper at the 10th Biennial Canadian Ethnic Studies Association Conference in Calgary in October 1989. 